\title{
Lymphedema of the upper extremity following circumferential burns
}

\author{
Chenicheri Balakrishnan MD, Lisa M Bradt RN, Abdullah J Khalil MD, John M Trupiano MD
}

C Balakrishnan, LM Bradt, AJ Khalil, JM Trupiano. Lymphedema of the upper extremity following circumferential burns. Can J Plast Surg 2004;12(2):79-80.

Lymphedema is characterized by edema of the extremity due to the inability of the lymphatic system to remove lymph into the circulation. This condition can result from destruction of the superficial lymphatics from burn injury and recurrent infection of the extremity. Due to its rare occurrence, two cases of upper extremity lymphedema following burns are reported.

\section{Lymphoedème des membres supérieurs, secondaire à des brûlures circonférentielles}

\begin{abstract}
Le lymphoedème se caractérise par l'œè̀me d'un membre en raison de l'incapacité du système lymphatique d'écouler la lymphe dans la circulation sanguine. Le problème de drainage peut résulter de la destruction des vaisseaux lymphatiques de surface par des brûlures ou des infections récidivantes. Comme ce genre d'événement se produit rarement, nous avons inclus dans le présent article la description de deux cas de lymphoedème des membres supérieurs, secondaire à des brûlures.
\end{abstract}

\section{Key Word: Lymphedema}

\begin{abstract}
T ymphedema occurs from the failure of the lymphatic system Lto remove macromolecules and fluid from the interstitial space. It is an unpleasant and difficult disease to treat. Persistent edema produces limitation of motion and facilitates fibrosis. Advanced disease results in a nonfunctional hand and upper extremity. The most common cause of chronic edema of the upper extremity is the effect of breast cancer treatment. Injury to venous channels and/or lymphatic channels results in lymphedema. Postoperative cellulitis and local effects of radiation can contribute to the development of chronic lymphedema.
\end{abstract}

\section{PATIENTS AND METHODS}

Over a four-year period, two patients previously treated for circumferential burns presented with late swelling of an upper extremity, with reduced function. Both patients has been treated by early excision followed by skin grafting. Graft take was satisfactory in both patients. Patients were started on early mobilization and pressure garments were used to control scarring.

\section{CASE PRESENTATIONS}

Case 1

A 44-year-old woman sustained circumferential burns of both upper extremities from a room heater. She had a history of seizure disorder and was on medication. She had escharotomy of the circumferential burns and was treated with excision and skin grafting on the second hospital day. Skin graft take was satisfactory and occupational therapy started two weeks following her injury. Pressure garments were used for six months to control scarring. Two years following injury, she presented with edema of the hand and fingers (Figure 1) and difficulty in moving the fingers. She gave a history of recurrent breakdown of the skin graft and gradual swelling of the hand which worsened over time. She was treated with antibiotics and compression therapy. With conservative management, the edema improved with limited function of the hand.

\section{Case 2}

A 28-year-old man presented with deep burns of his dominant right upper extremity following a house fire. He had significant inhalation injury and burns of the entire torso and face. He underwent early excision of his upper extremity burns with skin grafting and excision of his other burns. Due to inhalation injury, he required respiratory support for three weeks. His graft take was satisfactory and an exercise program was started at four weeks after injury. He continued to improve and wore his pressure garments for approximately nine months. Three years after the injury, he presented with swelling of the fingers and lack of function (Figures 2 and 3). He was treated with antibiotics, massage and compression therapy. The edema is under control with limited function of the hand.

\section{DISCUSSION}

Lymphedema is a condition characterized by swelling of the extremity from lack of drainage of the lymph into the circulation. Primary or congenital lymphedema is from aplasia or hypoplasia of the lymphatic system. Secondary lymphedema occurs from obstruction or damage to the lymphatics. The venous and lymphatic drainage from the hand is from a volar to dorsal direction. The main superficial trunks of the lymphatic system are located just superficial to the investing muscle fascia. The deep lymphatic system is located deep to the muscle, adjacent to the bone. Disruption of venous and lymphatic drainage from the distal extremity can occur from a variety of traumatic insults. Most upper extremity lymphedema is secondary to lymphedenectomy and/or radiation. Due to obstruction or destruction, there is an inadequate number of 


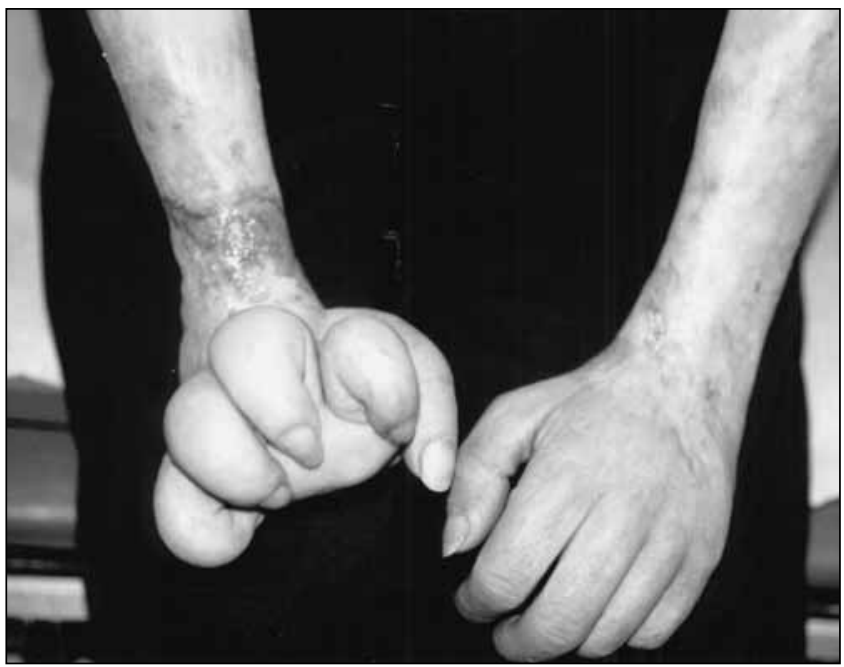

Figure 1) Ulceration of the forearm with edema of right hand in patient 1

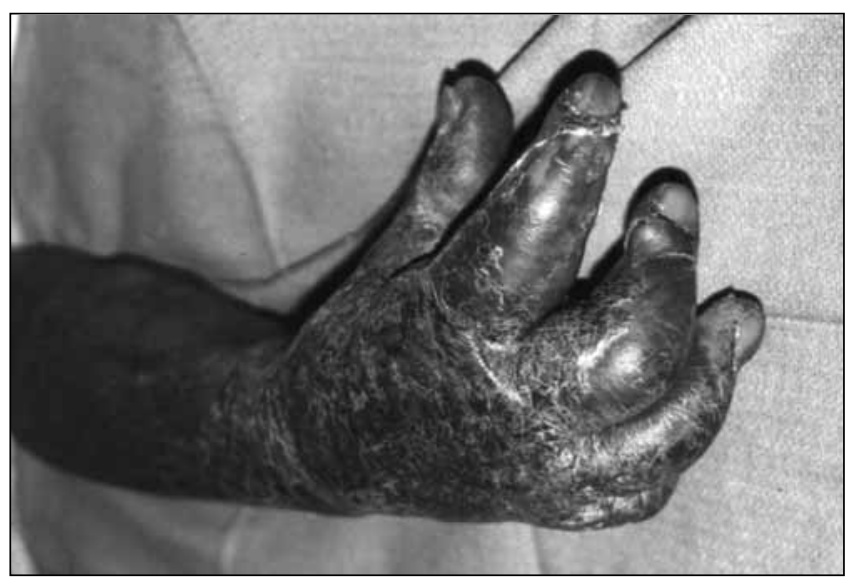

Figure 2) Lymphedema of the upper extremity in patient 2

lymphatic channels for removal of macromolecules from the interstitial fluid. The arm is heavy and fatigues easily. There is limitation in the range of motion in all joints.

Circumferential full thickness or deep partial thickness burns can occlude venous return; hence, escharotomy produces drastic resolution of distal congestion in early burn treatment. During debridement of a deep circumferential burn, the superficial lymphatics are removed. This causes relative obstruction of the lymphatic flow due to an inadequate number of lymphatic channels.

Recurrent episodes of lymphangitis have been reported in approximately $25 \%$ of patients with lymphedema (1). Due to the chronic inflammation, there is further destruction of the lymphatic channels leading to fibrosis of the connective tissue. Unfortunately, the fibrosis hinders venous and lymphatic flow. There is backpressure and this causes destruction of lymphatic collecting system. Ulceration and breakdown of the skin of the chronically lymphedematous extremity is suspicious of the occurrence of lymphangiosarcoma. It is often difficult to

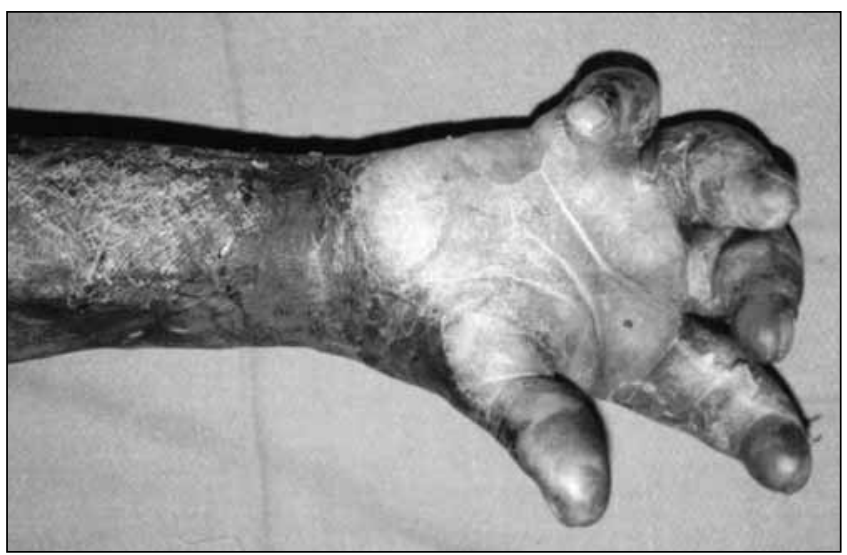

Figure 3) Lymphedema of the upper extremity in patient 2

distinguish between lymphatic and venous causes for edema of the extremity. Various methods used to differentiate the pathology include lymphangiography, ultrasonography and magnetic resonance imaging (2-4).

Lymphedema has been reported two to four years after debridement, free muscle transfer and delayed autologous bone grafting for open tibial fractures (5). Lymphedema has also been reported following debridement of extensive full thickness burns of the lower extremity (6). All these patients underwent escharotomy and excision of their circumferential burns followed by skin grafting. These patients presented nine months to two years after their injury and had a history of recurrent cellulitis of the extremity. Lymphedema of the lower extremity has been reported as a late complication of local burn, which healed by scarring. In this report, the patient developed gradual edema and flexion contracture of the extremity (7).

This condition is presently incurable and difficult to manage. Every attempt should be made to control edema and prevent infection. The elimination of swelling seems to ameliorate the symptoms. Elastic compression bandages and sequential compression may be helpful in controlling edema. Early diagnosis and management of infection is important in preventing morbidity in these patients.

\section{REFERENCES}

1. Schirger A, Harrison EG, Janes JM. Idiopathic lymphedema: Review of 131 cases. JAMA 1962;182:14-22.

2. Duewell S, Hagspiel KD, Zuber T, von Schulthess GK, Bollinger A, Fuchs WA. Swollen lower extremity: Role of MR imaging. Radiology 1992;184:227-31.

3. Doldi SB, Lattuada F, Zappa MA, Pieri G, Favara A, Micheletto G. Ultrasonography of extremity lymphedema. Lymphology 1992;25:129-33.

4. Crockett DJ. Lymphatic anatomy and lymphedema. Br J Plast Surg 1965;18:12-25.

5. Seyfer AE, Lower R. Late results of free-muscle flaps and delayed bone grafting in the secondary treatment of open distal tibial fractures. Plast Reconstr Surg 1989;83:77-84.

6. Balakrishnan C, Webber JD, Prasad JK. Lymphedema of lower extremities following debridement of extensive full skin thickness burns. Burns 1994;20:365-6.

7. Anand S, Lal H, Dhaon BK. Lymphedema of the lower extremity as a complication of local burns. Burns 1998;24:767-9. 